\title{
LEITURA E ESCRITA NA PERSPECTIVA DIALÓGICA DA LINGUAGEM: CONSTRUINDO SENTIDO NA EJA
}

\author{
Ramísio Vieira de Souza* \\ Janielly Santos de Vasconcelos Viana** \\ Maria de Fátima Almeida ${ }^{* * *}$
}

RESUMO: Este artigo apresenta os resultados da leitura e escrita na Educação de Jovens e Adultos (EJA) pautadas na perspectiva dialógica da linguagem de Bakhtin e o Círculo. Nesse âmbito, compreendemos a concepção de gênero do discurso como indispensável ao ato de ler e escrever na escola, por constituir práticas reais do uso da linguagem nos campos de atividades humanas. Propomo-nos a discutir os resultados do projeto de leitura e escrita nessa perspectiva, como também refletir sobre as experiências positivas, o uso da rede social e as dificuldades encontradas na execução das atividades pedagógicas propostas. O corpus é formado por duas produções textuais exportados do gênero whatsapp e duas imagens das aulas de uma turma do Ciclo IV da EJA. De posse dessas informações, selecionamos, analisamos e interpretamos as informações. Embasamos- nos principalmente em Bakhtin e o Círculo (2015); Base Nacional Comum Curricular- BNCC (2018); Almeida (2013); Diretrizes Curriculares Nacionais para a Educação de Jovens e Adultos (2000). Afirmamos que a leitura é resultado de um contrato que ocorre entre os participantes desse processo de construção de sentido na sala de aula.

PALAVRAS-CHAVE: Relações dialógicas; Leitura e escrita; EJA.

\footnotetext{
* Doutorando e mestre em Linguística pela Universidade Federal da Paraíba (UFPB).

** Doutoranda e mestre em Linguística pela Universidade Federal da Paraíba (UFPB).

${ }^{* * *}$ Doutora em Linguística pela Universidade Federal de Pernambuco (UFPE). Professora associada I do Departamento de Letras Clássicas e Vernáculas da Programa de Linguística (PROLING) da Universidade Federal da Paraíba (UFPB).
} 


\section{Introdução}

A escola é o lugar em que buscamos o desenvolvimento de habilidades e competências indispensáveis à formação do sujeito que participará ativamente da formação e desenvolvimento da sociedade. Então, as habilidades de leitura e escrita são fundamentais à formação do aluno e constituem etapas desafiadoras assumidas pelo professor na escola.

Compreendemos que ler e escrever, na perspectiva dialógica da linguagem, são atividades responsáveis pela transformação da realidade da escola, por apresentar o ato de ler como uma relação dialógica e interativa entre leitor/autor/texto, como afirma Almeida (2013), e a escrita como uma atividade enunciativa real, concreta, dinâmica, envolvente com finalidades bem definidas que atende as necessidades comunicativas dos sujeitos dentro dos campos de atividade humana.

Nessa concepção, o ponto de partida das aulas são os gêneros do discurso, isto é, os tipos relativamente estáveis de enunciados que são elaborados nos campos de atividade humana. Nesse sentido, propomo-nos a discutir alguns resultados do projeto de leitura e escrita, nessa perspectiva, como também refletir sobre as experiências positivas, o uso da rede social e as dificuldades encontradas na execução das atividades pedagógicas propostas.

O corpus é formado por duas produções textuais exportados do gênero whatsapp e duas imagens das aulas de leitura do Ciclo IV da EJA. De posse dessas informações, selecionamos, analisamos e interpretamos as informações. Embasamos- nos principalmente em Bakhtin e o Círculo (2015); Base Nacional Comum Curricular- BNCC (2018); Almeida (2013); Diretrizes Curriculares Nacionais para a Educação de Jovens e Adultos (2000).

Esperamos contribuir com pesquisas na perspectiva dialógica da linguagem, com o ensino da leitura e escrita e uso da linguagem no evento da vida. Na sequência, apresentamos uma breve discussão sobre as relações dialógicas, interação verbal, leitura e escrita.

\section{A perspectiva dialógica da leitura e escrita na sala de aula da EJA}

As relações dialógicas são constitutivas da linguagem e somente são possíveis entre diálogos integrais de diferentes sujeitos do discurso. Na perspectiva de Bakhtin e o Círculo 
(2015), elas surgem por meio dos enunciados de diferentes sujeitos que, quando em interação, produzem diferentes sentidos. Nesse processo, as relações linguísticas assumidas não podem ser analisadas somente pelo viés formal, porque o ato comunicativo é concreto, real e subjetivo. Então, é no evento da vida que os sentidos são produzidos e nas relações que assumimos com o outro, princípio de alteridade, que manifestamos nossos desejos, emoções, sentimentos, enfim, interagimos e constituímos a nós e ao outro. Nessa relação mútua, compreendemos a perspectiva dialógica como uma manifestação de vozes (atos) que aciona várias outras no processo de construção de sentidos.

Nesse âmbito, conforme Bakhtin (2015), as relações dialógicas são semânticas e ocorrem com toda espécie de enunciado na comunicação, isto é, dois ou mais, quando confrontados, em um plano de sentido real e concreto, acabam em relação dialógica. Os sujeitos, quando em interação, provocam o confronto de enunciados que intercruzam e produzem os sentidos, porque "[...] toda enunciação é uma "resposta", uma réplica, a enunciações passadas e a possíveis enunciados futuros, e ao mesmo tempo uma 'pergunta', uma 'interpelação' a outros enunciados” (SOBRAL, 2009, p. 33).

Assim, compreendemos que o enunciado está em relação dialógica com outros, pois eles são confrontados num plano de sentido, relacionado a um valor, como, por exemplo, a verdade, a beleza, exigindo uma compressão responsiva que já apresenta em si um juízo de valor, por isso que ela também é sempre dialógica. Dessa maneira, afirmamos que os enunciados não podem ser reduzidos a estudos mecânicos, limitados a estruturas formais, mas compreendidos em seus planos integrais, isto é, no contexto de uso em que são produzidos pelos sujeitos dotados potencialmente de sentidos.

O dialogismo fica mais claro quando Bakhtin (2015) trata da palavra como uma arena de conflitos sociais, ideológicos e históricos que forma o elo de enunciados que compõem o discurso nas interações comunicativas. O sujeito bakhtiniano, segundo Sobral (2009), é aquele que interage com outros sujeitos que são responsáveis por constituí-lo e também são constituídos por ele nas relações sociais permeadas pela linguagem. 
Em outras palavras, toda relação entre ao menos duas pessoas já é um evento social, uma relação social e histórica que envolve toda a sociedade, do ponto de vista de seus diferentes recortes possíveis num dado momento histórico, isto é, a relação entre duas pessoas traz à cena a soma total das relações sociais dessas pessoas, envolvendo no mínimo um espectro que vai da família ao Estado- e como estes só interagem, numa dada sociedade e num dado momento histórico, quando dois interagem, é de alguma forma o mundo que interage! (SOBRAL, 2009 p. 47-48)

Os sujeitos que participam desse evento social estão situados historicamente no tempo e espaço, e acabam permeados pelos discursos que os atravessam no ato comunicativo da linguagem. É esse aspecto dialético de que trata Bakhtin que fundamenta o que ele chama de dialogismo, constituindo não apenas o discurso, mas a linguagem e o agir do indivíduo nas relações sociais.

Dessa maneira, concebemos esse princípio da linguagem como fundamental nas aulas de leitura e escrita, porque as atividades constituem praticas discursivas reais do uso da linguagem na sala de aula. O evento denominado aula nada mais é do que uma relação de vozes que entram em confronto para a construção de um sentido que não pode ser qualquer um, mas aquele que é construído na relação dialógica entre os diferentes enunciados.

. A interação verbal é outro conceito bakhtiniano caro a nossa discussão, por se tratar de um fenômeno social que é realizado pela enunciação ou as enunciações entre os indivíduos. Ela não constitui um ato abstrato de formas linguísticas, nem enunciação monológica, mas um ato concreto e real do uso da língua. "A enunciação enquanto tal é um produto da interação social, quer se trate de um ato de fala determinado pela situação imediata ou pelo contexto mais amplo que constitui o conjunto das condições de vida de uma determinada comunidade linguística" (BAKHTIN; VOLOCHÍNOV, 2014, p. 126). Na interação verbal, a enunciação é organizada pelo meio social em que os sujeitos estão envolvidos. Por isso, que o fenômeno social da interação constitui a realidade da língua e não as formas linguísticas, enunciados monológicos isolados ou ato psicofisiológico de produção. 
Esse conceito se faz necessário, à medida que nos propomos a discutir a leitura e escrita na concepção dialógica da linguagem, porque a interação verbal é um fenômeno concreto do uso da língua nas situações comunicativas. O ato de ler na escola é uma atividade interativa permeada pela linguagem e constituem um evento comunicativo que acontece por meio da relação indissociável entre leitor/autor/texto, conforme Almeida (2013). A escrita constitui outra etapa que depende desta, porque para escrever algo preciso ler e produzir sentido.

Essa prática social da leitura e escrita tem como ponto de partida o gênero do discurso, isto é, o que Bakhtin (2015) denominou de "tipos relativamente estáveis de enunciados" que é produzido pelos campos de atividades humana. Eles são diversos e inesgotáveis, por atenderem as possiblidades multiformes das atividades humanas. Compreendemos que as aulas de leitura e escrita se tornam reais, quando partimos do estudo do gênero do discurso e propomos atividades de ler e escrever com foco na perspectiva dialógica da linguagem.

Em especial, a EJA carece de atividades dialógicas de leitura e escrita que façam parte da realidade do aluno, mas que também despertem para outras que ainda não tiveram a oportunidade de conhecer. Nesse âmbito, o professor assume um papel importante no preparo de atividades que torne o aluno protagonista do seu aprendizado e não mero receptor de informações e conteúdos. A aula de leitura passa a ser um evento de interação e construção prazerosa de sentido e não somente com a finalidade de atribuir uma nota, mas despertar o gosto ainda mais por ela e conhecer outras realidades. A escrita passa a ter uma finalidade definida pelos autores do processo e se torna uma realidade de uso, produção e veiculação de informação.

Apesar da Lei de Diretrizes e Bases da Educação- LDB (Lei No 93.94), de 20 de dezembro de 1996, abordar a EJA como uma modalidade destinada àqueles que não tiveram acesso ou continuidade de estudos nos ensinos fundamental e médio na idade regular e afirmar que os sistemas de ensino terão que garantir oportunidades educacionais apropriadas, como também o Poder Público que viabilizará e estimulará o acesso e a permanência 
do trabalhador, verificamos, por parte das políticas públicas educacionais, uma ausência de estímulo para essa modalidade da educação. Isso fica mais evidente quando consultamos a Base Nacional Comum Curricular (2018) em que constatamos apenas uma menção rápida à EJA. Esse fato encoraja estudiosos da linguagem e educação a criar uma política de resistência em relação ao silêncio dessas vozes que também têm o direito de estudar.

Então, o artigo também é uma forma de resistência ao silêncio das vozes oprimidas e enfraquecidas da EJA na sua batalha por espaço e divulgação no decorrer da educação. Apresentamos exemplos de trabalhos em que o aluno da EJA foi participante ativo do aprendizado e compreendeu que é capaz de transformar a sua realidade e a do outro por meio da leitura e escrita.

Afirmamos, portanto, a importância da abordagem dialógica da leitura e escrita na sala de aula da EJA e compreendemos que o ato de ler e escrever são atividades dinâmicas e interativas que juntas transformam a realidade da escola.

\section{Vivências dialógicas nas aulas de leitura e escrita da EJA}

As vivências do projeto "Ler e escrever na EJA na perspectiva dialógica da linguagem" são diversas, mas aqui iremos apresentar um reconte de momentos e produções realizadas no evento da aula e refletimos sobre a relevância dos conhecimentos compartilhados pelos alunos da EJA nas situações cotidianas que, quanto confrontados no ato de ler, produzem relações dialógicas que resultam na compreensão ativa responsiva na sala de aula. Dizemos responsiva, conforme Bakhtin (2015), porque, na atividade de leitura, o aluno concorda, discorda e refuta informações. Essas relações dialógicas são os fios que tecem as compreensões ativa do discurso da aula.

O projeto teve duração de quatro meses e foi aplicado a uma turma de 20 alunos da EJA do ciclo IV de uma escola do município de João Pessoa com a finalidade melhorar o gosto dos alunos pela leitura e escrita na escola.

Primeiramente, formamos uma roda de conversa e discutimos a importância do ato de ler e escrever na sociedade brasileira. Dessa experiência, retiramos informações acerca 
das dificuldades de leitura e identificamos, nos relatos orais, a leitura de alguns gêneros do discurso relacionado ao campo pessoal de atividade humana, como manuais de instruções, revistas de culinária, de produtos de beleza, entre outros. Esse diagnóstico prévio foi essencial para avaliarmos o que eles já conheciam, isto é, quais gêneros circulavam no cotidiano deles e quais eles precisavam conhecer.

Nesse contexto, já que havíamos dialogado abertamente sobre ler e escrever e apresentamos sugestões de obras, a turma escolheu democraticamente o romance Os miseráveis, uma adaptação de Walcyr Carrasco da obra original do francês Victor Hugo. Essa escolha também é justificada pela quantidade de exemplares que a escola dispõe por proporcionar o contato com o livro a todos da turma. Ademais, escolheram um dia da semana para realizar a aula de leitura.

Essa escolha coletiva e democrática do ato de ler na escola proporciona um maior engajamento e estímulo a essas atividades na escola. Iniciamos a leitura como prazer e sem gerar cobrança com finalidades avaliativas. Na primeira etapa, conhecemos os autores e refletimos sobre as suas biografias. Para na aula seguinte, iniciamos a leitura da obra. No final de cada capítulo foram realizados comentários orais e questionamentos reflexivos para a leitura do capítulo seguinte. Essa Estratégia de leitura proporcionou a curiosidade e o desejo de ler a obra na íntegra.

Dessa forma, compreendemos a importância do planejamento do professor e o levantamento prévio de estratégias para a mediação do ato de ler na escola. Afirmamos também que a leitura é resultado de um contrato que ocorre entre os participantes desse processo de construção de sentido na sala de aula. Além disso, não há como dissociar o leitor/autor/texto, como afirma Almeida (2013), porque é na interação dessa tríade que os sentidos são construídos, afinal eles não são fixos, mas fruto das relações dialógicas que ocorrem no processo interativo da linguagem.

Essa prática da leitura foi responsável por mudar a realidade da EJA e transformar a aula num espaço de democratização do conhecimento e de aprendizado mútuo, porque 
ocorreu a relação de vozes aluno/aluno, aluno/professor, aluno/texto e professor/texto. Nesse espaço, o ensino da leitura se tornou agradável e prazeroso.

Figura 1- Momento de leitura

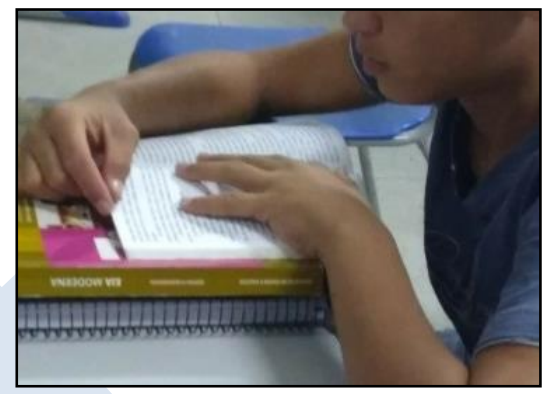

Fonte: Arquivo pessoal dos professores.

Figura 2- Momento de leitura

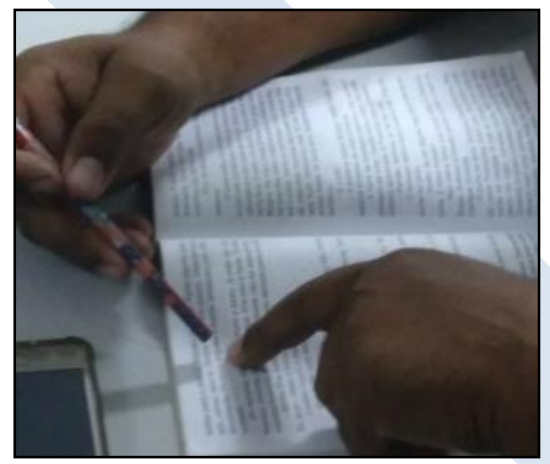

Fonte: Arquivo pessoal dos professores.

Nas figuras 1 e 2, os alunos estão acompanhando a leitura realizada pelo colega. $\mathrm{Na}$ segunda figura, percebe-se a atenção do aluno para com o texto e a preocupação de acompanhar minuciosamente o ato de ler. Esse fato pode ser sinal de um leitor ainda não proficiente, notado pelo apontar do dedo em relação às palavras, como se necessitasse de uma decodificação das sílabas e, consequentemente, das palavras para compreendê-las no todo. 
Na primeira figura, o aluno encontrasse atento ao ato de ler e apoiado no livro, mas apresenta a visão aberta da leitura, o que indica um leitor mais proficiente e com uma experiência maior de leituras.

Essas marcas discursivas do texto verbo- visual revelam os diferentes leitores que a EJA apresenta e mostram o quanto é urgente o ensino de ler na escola. Nesse sentido, tendo em vista a interação proporcionada pelas aulas de leitura, decidimos, democraticamente, tecer relações dialógicas com o projeto interdisciplinar "Tecendo diálogos com Analice Rodrigues Uchoâ"20 que foi desenvolvido em outras aulas. Nesse sentido, usamos o suporte whatsapp como ferramenta de incentivo a leitura e escrita, assim como ferramenta de compartilhamento dos capítulos lidos para aqueles que, por algum motivo, não participaram da aula.

Figura 3- Compartilhamento de capítulos lidos para alunos faltosos

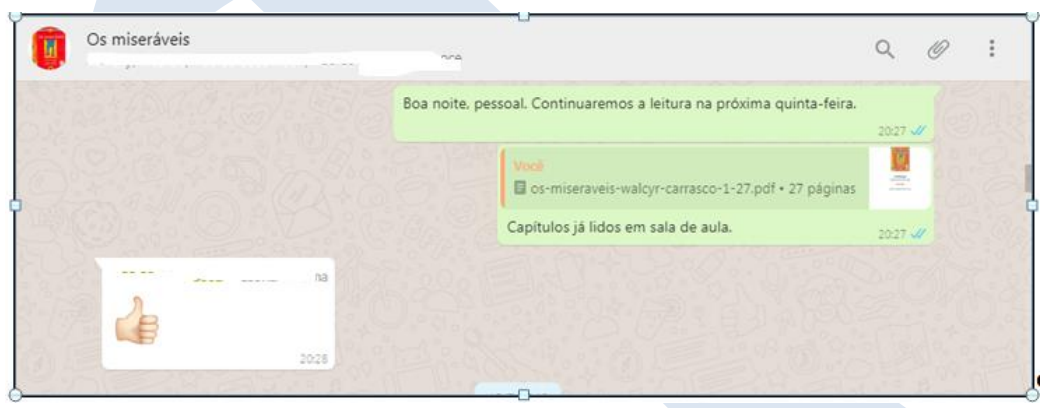

Fonte: Captura de tela do Whatzapp

No exemplo, o professor estabelece a interação com os alunos, apresenta o dia da próxima leitura e disponibiliza os capítulos já lidos em sala de aula. Então, as mídias sociais

20 Nasceu em 02 de setembro de 1948, natural de Campina Grande-PB. É artista plástica paraibana. Em seus trabalhos ela expõe a temática que contempla o universo da cultura popular, com ritos e mitos, festas e costumes, indo da cidade ao campo, relatando comportamentos, modos de vida e de expressão do povo nas suas manifestações originais. Disponível em: http://www.paraibacriativa.com.br/artista/analice-rodrigues-uchoa/. Acesso em 12 de fevereiro de 2019. 
são ferramentas indispensáveis à prática de leitura e escrita em sala de aula, como se constata na exemplificação da execução dos projetos na escola. Esse gênero do discurso Whatsapp foi fundamental na execução das atividades, porque é a rede social presente no cotidiano do aluno da EJA, isto é, relacionado ao campo pessoal. Dessa forma, criamos um grupo com a finalidade pedagógica para compartilhar os capítulos lidos para os ausentes, produzir textos e democratizar o conhecimento produzido no ambiente escolar. Ressaltamos a importância do contrato com os alunos a respeito da funcionalidade do grupo, para amarrar bem as ideias e não vir a desvincular do propósito educativo.

Figura 4- Produção escrita

07/08/18 3:31 PM - R Minha pequena fazenda, onde
moramos no meio do mato, e de noite ouvimos os grilos cantarem logo
cedo, acordo para ver o sol raiar, cuidar das Cabras e tomar aquele
café que só seu chico sabe fazer doce e bem quentinho para o frio matar
, tio Zé acorda para ir trabalhar e da casa eu e Chico cuidar, de
meio-dia eu vou buscar as cabras para tomar água, depois eu vou
almoçar, aqui er casa só tem homens , sou eu meu tio Zé e seu Chico o
caseiro, cozinheiro, e tocador de violão, tio Zé sempre diz
- respeito o Chico enquanto estou fora. seu Chico responde
- ele é um bom garoto.
Assim vivo na minha fazenda ouvindo seu chico tocar sua viola, ,
enquanto se balanço na rede na varanda de minha bela fazendinha.
\#Alunos : R , $\mathrm{S}$,

Fonte: Exportação da conversa do Whats App.

Na figura 4, apresentamos a produção dos alunos R, S e W21 e verificamos a presença de um texto narrativo, proposta acordada nas aulas, a partir da leitura verbo- visual das telas de Analice e dos conhecimentos adquiridos ao longo das aulas. Verificamos as relações dialógicas de aproximação com olhar artístico dessa artista que apresenta temáticas relacionadas ao campo. Eles se apossam do discurso veiculado nas obras, por trazer a presença desse narrador- personagem ("Minha pequena fazenda", "Assim vivo na minha fazenda").

21 Com a finalidade de preservar a identidade dos sujeitos autores dos textos, adotamos a identificação por letras. 
Essas marcas linguísticas mostram a produção de sentido através dos fios dialógicos que atravessam os discursos na relação leitor- produtor/autor/texto. A circulação do texto por meio da rede social proporcionou a divulgação do texto e incentivo a outras produções textuais, principalmente, daqueles que não haviam realizado a atividade.

Figura 5- Produção escrita

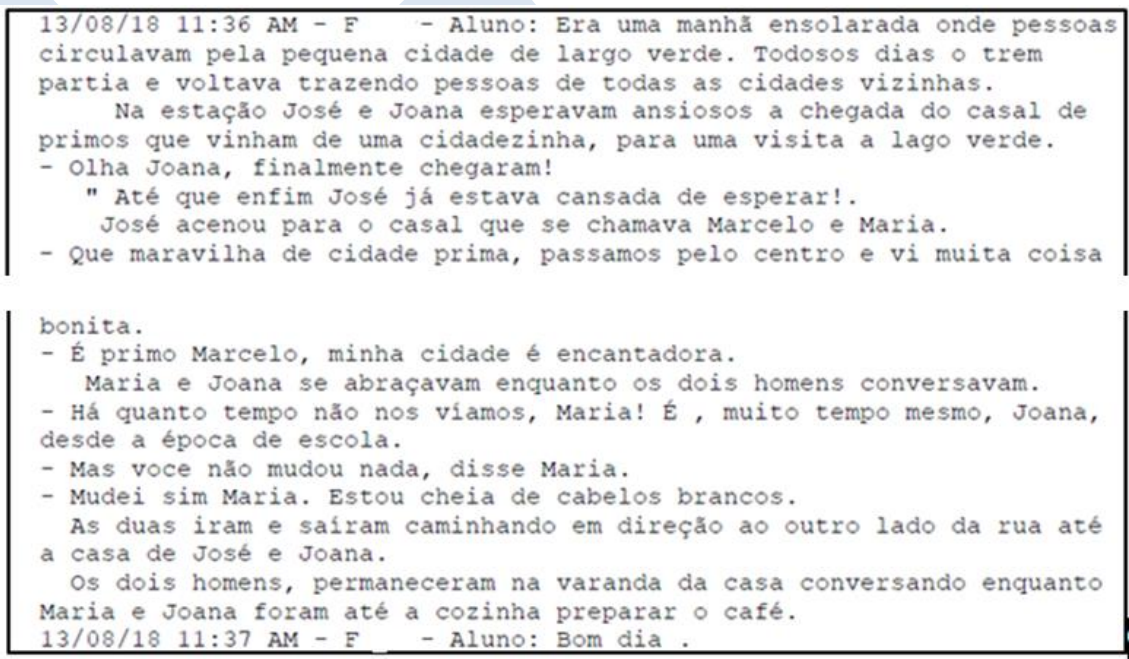

Fonte: exportação da conversa do Whats $A p p$.

Nessa figura 5, apresentamos mais uma produção dos alunos a partir da leitura das telas de Analice e percebemos uma estrutura inicial de uma narrativa que já apresenta característica de um conto. $\mathrm{O}$ aluno $\mathrm{F}$ apresenta as marcas temporais do passado, indicada pelos verbos (era, circulavam, partia, voltava), como também pela presença de um narrador observador que narra os fatos e a presença de poucos personagens. A presença marcada do discurso direto, indicando a fala dos personagens. Além disso, o diálogo com a obra da artista está presente por meio da descrição dos lugares (pequena cidade de largo verde), pois suas obras apresentam um contraste entre o campo e a formação urbana das pequenas cidades. 
Afirmamos a perspectiva dialógica da linguagem como essencial no desenvolvimento das atividades de leitura e escrita por abordar o gênero do discurso como uma prática real de uso da linguagem. O sujeito interage no evento da vida e adquire experiências, quando em interação com outro, que produz os feixes de sentidos. Então, eles não apresentam um lugar fixo, mas são construídos a partir das relações dialógicas entre os interlocutores nas atividades comunicativas da linguagem.

Finalmente, ressaltamos também as dificuldades encontradas ao longo do desenvolvimento dos projetos, como a desmotivação do aluno, falta de internet na escola, dificuldades de acesso aos multimeios (tv, som, datashow, computador). Apesar desses fatores negativos, as atividades não deixaram de ser executadas e verificamos uma maior motivação dos alunos e participação nas atividades de leitura e escrita na sala de aula.

\section{Algumas considerações}

Nesse artigo, refletimos sobre o trabalho com projetos de leitura e escrita na perspectiva dialógica e apresentamos a relevância para a democratização da aula, engajamento do aluno e participação ativa na construção do sentido. O aluno da EJA teve a oportunidade de conhecer textos ligados ao campo literário e ler de forma prazerosa. Além disso, verificou- se a construção de sentido na sala de aula e a formação de leitor crítico e criativo, capaz de decidir sobre as próprias leituras.

Compreendemos também a valorização conhecimento de mundo são essenciais no desenvolvimento das atividades escolares. Ademais, o engajamento das atividades do projeto “Tecendo diálogos com Analice Rodrigues Uchoâ" também foi fundamental no ato de ler e escrever, porque o texto verbo- visual abordou diferentes temáticas, como o campo e a cidade, que foram motivadoras das produções narrativas. A circulação dos textos na rede social Whats $A p p$ também tornou a aula interativa e proporcionou o contato com o texto do colega, assumindo a função não somente de autor, mas também de leitor dos autores da aula. 
Portanto, defendemos o uso das mídias sociais para fins pedagógicos, como também a capacitação dos profissionais para atender as demandas da tecnologia da informação a serviço das pessoas do mundo globalizado. O papel do professor se torna fundamental na compreensão dos usos das diferentes linguagens no mundo virtual.

\title{
READING AND WRITING IN THE LANGUAGE DIALOGUE PERSPECTIVE: BUILDING SENSE IN THE EJA
}

\begin{abstract}
This article presents the results of reading and writing in Youth and Adult Education - EJA based on the dialogical perspective of Bakhtin's language and the Circle. In this context, we understand the concept of discourse genre as indispensable to the act of reading and writing in school, as it constitutes real practices of the use of language in the fields of human activities. We propose to discuss the results of the reading and writing project in this perspective, as well as reflect on the positive experiences, the use of the social network and the difficulties encountered in the implementation of the proposed pedagogical activities. The corpus is made up of two textual productions exported from the genre whatsapp and two images from the classes of an EJA Cycle IV class. In possession of this information, we select, analyze and interpret the information. We rely mainly on Bakhtin and the Circle (2015); Common National Curriculum Base - BNCC (2018); Almeida (2013); National Curriculum Guidelines for Youth and Adult Education (2000). We affirm that reading is the result of a contract that occurs between the participants of this process of meaning making in the classroom.
\end{abstract}

KEYWORDS: Dialogical relations; Reading and writing; EJA.

\section{REFERÊNCIAS}

ALMEIDA, Maria de Fátima. As múltifaces da leitura: a construção dos modos de ler. Graphos (João Pessoa), 2008.

- O desafio de ler e escrever: experiências com a formação docente. [recurso eletrônico] / Maria de Fátima Almeida. - João Pessoa: Ideia Editora, 2013.

- Os movimentos discursivos do leitor na construção do sentido na sala de aula. João Pessoa: Editora Universitária/UFPB, 2013, v.1. p. 227. ideia, 2015.

. Vivências dialógicas: entre a teoria e ensino de língua portuguesa. João Pessoa:

BAKHTIN, Mikhail. (1895-1975). Os gêneros do discurso. Tradução: Paulo Bezerra. São Paulo: Ed. 34, 2016. 
2015.

. Estética da criação verbal. Tradução: Paulo Bezerra. São Paulo: Martins Fontes,

. (Volochínov). [1929]. Marxismo e filosofia da linguagem: problemas fundamentais do método sociológico na ciência da linguagem. [Trad. M. Lahud e Y. F. Vieira]. 16 ed. São Paulo: HUCITEC, 2014.

- (1895-1975). Teoria do romance I: A estilística. Tradução: Paulo Bezerra. São

Paulo: Ed. 34, 2015.

BRASIL. Lei de Diretrizes e Bases da Educação Nacional. Lei número 9394, 20 de dezembro de 1996.

BRASIL, Ministério da Educação. Base Nacional Comum Curricular. Proposta preliminar, $2^{\mathrm{a}}$ versão revisada. Brasília: MEC, abril de 2018.

FARACO, Carlos Alberto. Linguagem \& diálogo: as ideias do círculo linguístico de Bakhtin. São Paulo. Ed.: Parábola, 2009.

Brasil. Secretaria de Educação Fundamental. Parâmetros curriculares nacionais: língua portuguesa. Secretaria de Educação Fundamental. - Brasília, 1998.

CARRASCO, Walcyr. Os miseráveis. 2. ed., rev. São Paulo: Moderna, 2012. col., 23 cm. (Biblioteca Walcyr Carrasco. Clássicos universais).

UCHÔA, Analice. A mão que pinta o destino. Disponível em: https:/ /www.catalogodasartes.com.br/artista/Analice\%20Uchoa/. Acesso em: 29 de maio de 2018.

Recebido em: 01/09/2019. Aprovado em: 30/10/2019. 